\title{
STRATEGY OF CONTAINER ASSEMBLY FOR A POSITIVE ENERGY IMPACT IN POONA INDIA
}

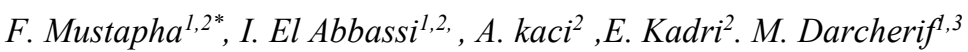 \\ ${ }^{1}$ Laboratoire de Recherche en Eco-innovation Industrielle et Energétique, ECAM-EPMI, Cergy-Pontoise \\ ${ }^{2}$ Laboratoire de Mécanique et Matériaux du Génie Civil, Université de Cergy-Pontoise. \\ ${ }^{3}$ Laboratoire QUARTZ, (EA 7393), Université Paris-Seine.
}

\begin{abstract}
Every year the Indian government is involved in the construction of nearly two million new buildings excluding the tertiary sector. These homes are not only intended primarily to house Indian populations, but the authorities concerned have also placed emphasis on sustainable development, since as all over the world the residential sector is the one that consumes the most energy. Indeed, active and passive strategies to reduce the energy consumption of dwellings have been established and even applied. Among the passive strategies, the global shape of the building, initially specific to modular architecture impacts the aesthetic part of the building but also its energetic bills. The concept of modular architecture is mainly the assembly of identical cells and, in different ways, the overall energy consumption depends on the initial assembly of the cells and therefore on the resulting shape of this assembly. The purpose of this article is to determine the impact of the shape on the energy balance. For this study, the container is the archetype used, in fact the metal box being a standardized, economical and easily transformable product in living space. The complex system resulting from the assembly of several containers offers a new way of thinking about housing from an architectural, economic, aesthetic and energetic point of view. In this article, we will focus on studying the impact of the overall shape of container-type housing on annual energy bill, with the aim of optimizing energy efficiency and achieving an eco-container model that meets international eco-sustainability criteria. The results demonstrate the undeniable correlation between geometric and energy aspects, the latter being mainly related to the internal thermal comfort of the container housing cells.
\end{abstract}

\section{INTRODUCTION}

The energy transition is a global issue, precisely for the residential sector, one of the most energy consuming in terms of heating, cooling or lighting, the success of this transition must not be at odds on the user who remains the first consumer, human and housing interaction is very present because the environment has a direct impact on the mental and physical well-being of the individual, rethinking user comfort is a multi-faceted, aesthetic, economic and thermal task, the latter is on the centrepiece of all government and local initiatives.

The reduction of the energy bill is done by optimizing the overall consumption of the building [1], to do so, existing solutions are applied by all the project managers, including passive architecture, which consists in intervening on several levels, the first is the envelope using natural and local materials, then the definition of the thicknesses of the materials and their physical and thermal characterization, the proportion of the size of the glazing compared to the facade, WWR (Windows to Wall Ratio), this last impact considerably the quantity of energy acquired or lost by the whole house. Other passive strategies exist such as geometry, in which interest is growing, this criterion impacts both the aesthetic aspect of the building and its energy efficiency, expressed in heating or air conditioning needs [2].

Many studies have been conducted on the subject of energy transition, and especially on its ecological flight, these surveys now encourage architects to extend their creativity towards the reuse of materials and have a recycling approach, among these concepts, container-type architecture, which was recommended for its economic benefits and speed of execution [3].

In this article, we will focus on this archetype, used in the residential sector, in order to evaluate the impact of geometries on the overall energy bill, and since the Indian climate and more particularly the city of Poona is considered to be hot or even semi-arid, with an annual average of temperature varying between $20^{\circ}$ and $28^{\circ} \mathrm{C}$ [4], this is why the primary interest will focus on the treatment of air conditioning or cooling demand. This comparative study will focus on dwellings made in containers with different morphologies but with the same inner surface area and therefore the same number of container cells. Indeed, having a different assembly necessarily implies a different energy efficiency, aware that the container, initially designed for the logistical sector, represents a cell standardized by the international standardization

\footnotetext{
*Corresponding author: f.mustapha@ecam-epmi.com
} 
organization [5]. As such the 20' container has the following dimensions: W: $6058 \mathrm{~mm}$; H: $2591 \mathrm{~mm}$; I: 2438 $\mathrm{mm}$; taking into account these information's and the thermal performance of the envelope and the materials that compose it in order to proceed on numerical study on TRNSYS by applying all the passive strategy principals.

\section{Methodology}

\subsection{Model definition:}

The first step consisted in the definition of the envelope and its materials, for this purpose, Table 1 \& figure 2 highlights the types of walls used as well as the U-value relating to each one. Then the choice was made for the total number of containers, which is 8 cells in layout. For a total surface area of $110.88 \mathrm{~m}^{2}$. before moving on to simulations on Trnsys, it is necessary to define the input data for each cell, first the use scenario that is typical for a house (see Figure 1) and which is equivalent to the occupancy schedule, then a natural ventilation was imposed. Given the local climate of Poona, the heating will never be active, so the cooling system is the only one imposed with a set temperature of $25^{\circ} \mathrm{C}$, other parameters are also taken into account by the software which are as follows:

- Meteorological data: the weather data of Poona India (meteonorme of TRNSYS17)

- Atmospheric pressure: $101325[\mathrm{~Pa}]$.

- Heat of vaporization of water: $2454[\mathrm{~kJ} / \mathrm{kg}]$.

- Stefan Boltzmann Constant: $2.041 \mathrm{e}^{-007}$ $\left[\mathrm{kJ} / \mathrm{hm}^{2} \mathrm{~K}\right]$.

- Approximation of average surface temperature: $293.15[\mathrm{~K}]$.

Table 1. Wall type of the container

\begin{tabular}{|c|c|c|c|}
\hline Wall type & Materials & $\begin{array}{c}\text { Thickness } \\
{[\mathbf{m}]}\end{array}$ & $\begin{array}{c}\text { U-Value } \\
{\left[\mathbf{W} / \mathbf{m}^{2} \mathbf{K}\right]}\end{array}$ \\
\hline \multirow{4}{*}{ Out wall } & Wall board & 0.013 & \multirow{4}{*}{0.093} \\
\hline & $\begin{array}{c}\text { Wood } \\
\text { Structure and } \\
\text { Air gap }\end{array}$ & 0.05 & \\
\hline & Hamp wool & 0.12 & \\
\hline & $\begin{array}{c}\text { Corten steel } \\
\text { structure }\end{array}$ & 0.08 & \\
\hline \multirow{3}{*}{ Windows } & Glass & 0.004 & \multirow{3}{*}{1.4} \\
\hline & Air gap & 0.016 & \\
\hline & Glass & 0.004 & \\
\hline \multirow{4}{*}{ Roof } & Wall board & 0.013 & \multirow{4}{*}{0.470} \\
\hline & $\begin{array}{c}\text { Wood } \\
\text { Structure and } \\
\text { Air gap }\end{array}$ & 0.05 & \\
\hline & Hamp wool & 0.12 & \\
\hline & $\begin{array}{c}\text { Corten steel } \\
\text { structure }\end{array}$ & 0.08 & \\
\hline Ground & $\begin{array}{c}\text { Keruing } \\
\text { wood }\end{array}$ & 0.15 & 0.852 \\
\hline
\end{tabular}

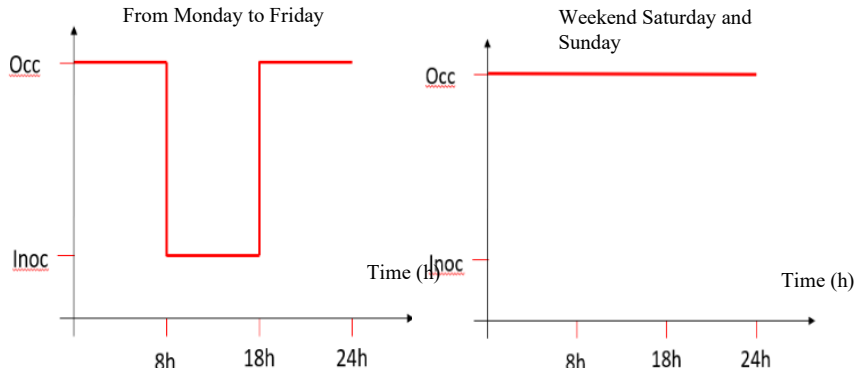

Fig. 1. Users scenario during the week (unoccupied "inc" occupied "occ")

\subsection{Simulation Process:}

The next phase of the study consist on the definition of the geometries specific to each configuration, we want to demonstrate the impact of morphology on the primary demand for cooling energy, the strategy chosen and to vary the designs according to a criterion which is the number of exposed surfaces, and therefore naturally vary the compacity of these container assembly. The first objective is not only to reduce the energy consumption of the building only with the overall shape but also to increase the indoor comfort for the user. These containers layouts are described on the table below (See Table 2 \& Figures 3-6)

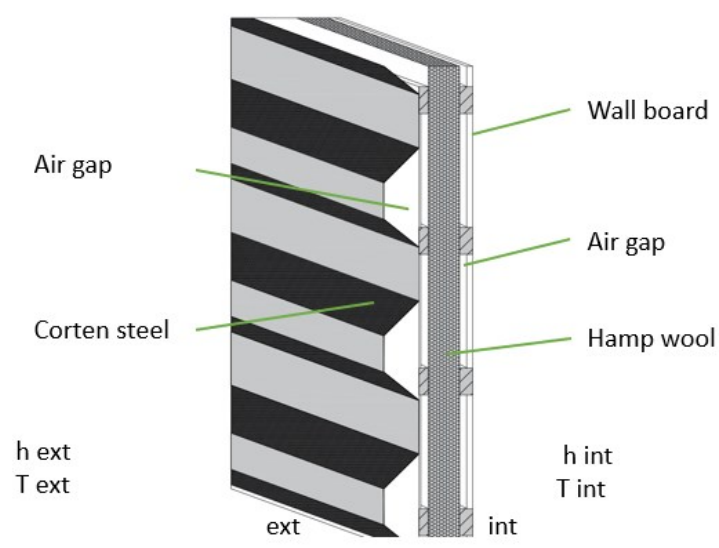

Fig. 2. Axonometric wall section

Table 2. Configurations descriptions

\begin{tabular}{|l|c|c|}
\hline Configurations & $\begin{array}{c}\text { Perimeters (number of } \\
\text { exposed facades) }\end{array}$ & $\begin{array}{c}\text { Surfaces } \\
{\left[\mathbf{m}^{\mathbf{2}}\right]}\end{array}$ \\
\hline Configuration a & 12 & 216.10 \\
\hline Configuration b & 14 & 244.30 \\
\hline Configuration c & 16 & 243.82 \\
\hline Configuration d & 18 & 272.02 \\
\hline
\end{tabular}


Ours models present the same solar exposition, in fact all the doors are oriented west, and all the windows are oriented south, and a WWR around 20\%.

When the simulation is launched, results representing an hour-by-hour assessment of the studied area for the whole year, this numerical calculation is based on the following equation (see equation (1)):

$$
\begin{aligned}
& Q b a l=D Q_{\text {air }}+Q_{\text {heat }}-Q_{\text {cool }}+Q_{\text {vent }}+Q_{\text {inf }} \\
& +Q_{\text {trans }}+Q_{\text {gainint }}+Q_{\text {sol }}
\end{aligned}
$$

Where : Qbal represents the energy bal of the set geometry.

$\mathrm{d}$ Qair/dt: Indicates the variation in enthalpy of the air in the zone, it reflects either a decrease or an increase in temperature. $[\mathrm{kJ}]$

QHEAT: Indicates the heating requirements by the system to reach the set temperature. [kJ]

Q to reach the cooling setpoint temperature. $[\mathrm{kJ}]$

QINF: Indicates losses through infiltration. [kJ]

QvENT: Indicates losses through ventilation. [kJ]

QTRANS: Indicates losses related to wall transmissions. (Surface and linear losses). [kJ]

Q $_{\text {GAININT: Indicates internal inputs. [kJ] }}$

$\mathrm{Q}_{\mathrm{SOL}}$ : Indicates internal gains related to solar gains (short waves). [kJ]

The thermal energy transfer rates of ventilation air infiltration and flow are calculated by the following equations, respectively :

$$
\begin{gathered}
Q_{\text {inf }}=m_{\text {inf }} C_{\text {air }}\left(T_{\text {air }}-T_{\text {ext }}\right) \\
Q_{\text {vent }}=m_{\text {vent }} C_{p}\left(T_{\text {vent }, \text { ext }}-T_{\text {vent }, \text { int }}\right) \\
Q_{\text {trans }}=S h_{\text {conv }}\left(T_{\text {surf }}-T_{\text {air }}\right)
\end{gathered}
$$

Where :

$m_{\text {inf }}$ : Air flow rate due to infiltration $[\mathrm{kg} / \mathrm{s}]$

Cair: The specific heat of the air is assumed to be constant and estimated at 1008 [m2 s- 2 K-1, d kg-1 K-1]

$C p$ : specific heat [J kg-1 K-1]

$m_{\text {vent }}$ : Air circulation due to ventilation $[\mathrm{kg} / \mathrm{s}]$

$\mathrm{T}_{\text {air }}$ : Air temperature $\left[{ }^{\circ} \mathrm{C}\right]$

$h_{\text {conv }}$ : Coefficient of heat flux exchanged by convection [w m-2 K-1]

$S$ : the solar factor, represents the total amount of energy that is allowed to pass through glazing in relation to incident solar energy.
The gross requirements representing the total losses of the building are the addition of $\mathrm{Q}_{\mathrm{TRANS}}+\mathrm{Q}_{\mathrm{INF}}+\mathrm{Q}_{\mathrm{VENT}}$ and the free contributions are the sum of $\mathrm{Q}_{\text {GAININT }}+\mathrm{Q}_{\text {sol }}$ that we subtract from the total losses in order to know our net requirement which is the cooling requirement.

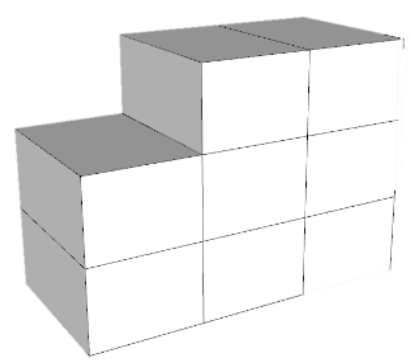

Fig. 3. Configuration a

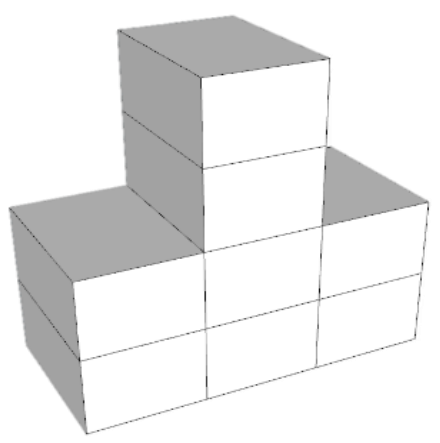

Fig. 4. Configuration $b$

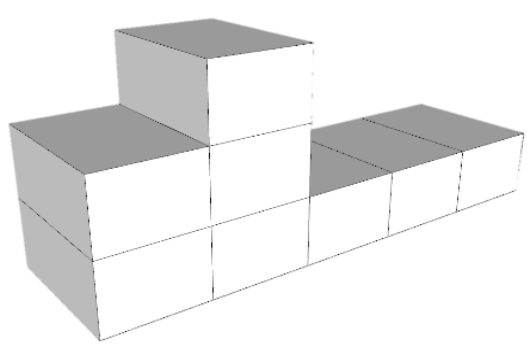

Fig.5. Configuration c

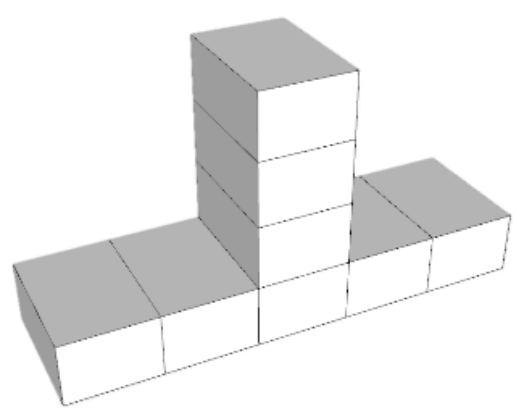

Fig. 6. Configuration d 
In the next step of the study is to study the compactness ratio relative to each geometry, we have chosen to define it by the ratio of the spreading of geometry on the ground and exposed surfaces (see equation 2). The interest of this part is demonstrated by the extent of its impact on the energy balance.

$R c=\frac{\text { Aext }}{A f}$

Where:

$\mathrm{Rc}$ is the ratio of compacity.

Aext: represents the external area $\left[\mathrm{m}^{2}\right]$.

Af: represents area of the ground $\left[\mathrm{m}^{2}\right]$.

Table 3. Compacity ratio by configuration

\begin{tabular}{|c|c|c|c|}
\hline $\begin{array}{c}\mathbf{R c} \\
\text { configuration } \\
\mathbf{a}\end{array}$ & $\begin{array}{c}\mathbf{R c} \\
\text { configuration } \\
\mathbf{b}\end{array}$ & $\begin{array}{c}\mathbf{R c} \\
\text { configuration } \\
\mathbf{c}\end{array}$ & $\begin{array}{c}\mathbf{R c} \\
\text { configuration } \\
\mathbf{d}\end{array}$ \\
\hline 5.20 & 5.88 & 3.52 & 3.93 \\
\hline
\end{tabular}

The energy balance produced by TRNSYS on the proposed models has been simulated for a year with a time step of one hour. The hourly results were integrated to obtain the monthly and annual summaries in the results section.

\section{Results}

The results show an improvement in terms of cooling energy demand, especially configuration $\mathrm{c}$, which gives a better profitability (see Table ), this geometry presents not only an economy but also a considerable exposed roof area $69.3 \mathrm{~m}^{2}$. This morphology is interesting from an architectural point of view, the latter has an irregular reading and Skyline with a difference in level in steps, which in turn provides a specific shading that improves indoor comfort, and thus directly impacts the energy efficiency of the design.

As our model is a container with a metallic outer shell, this highly conductive material makes it possible to benefit from natural heat.

The configurations a \& b show a similarity both in terms of compacity ratio and cooling demand, but at the formal level the two designs are indeed different, configuration a has only one lateral layer and therefore one possibility of exploitation, while configuration $b$ has two lateral surfaces that can be used later on, during the space distribution and interior design phase.

Table 4. Energy balance by configurations during a year

\begin{tabular}{|c|c|c|c|c|}
\hline Configurations & $\begin{array}{c}\text { Configura } \\
\text { tion a }\end{array}$ & $\begin{array}{c}\text { Configura } \\
\text { tion b }\end{array}$ & $\begin{array}{c}\text { Configura } \\
\text { tion c }\end{array}$ & $\begin{array}{c}\text { Configura } \\
\text { tion d }\end{array}$ \\
\hline $\begin{array}{c}\text { QCOOL }[\text { KWh } \\
/ \text { Year] }\end{array}$ & 34361.11 & 34444.44 & 33583.33 & 35055.56 \\
\hline $\begin{array}{c}\text { QINF [KWh } \\
\text { /Year] }\end{array}$ & -79.78 & -77.67 & -78.56 & -71.75 \\
\hline $\begin{array}{c}\text { QTRANS [KWh } \\
\text { /Year }]\end{array}$ & -3230.56 & -3097.22 & -2289.17 & -2474.17 \\
\hline $\begin{array}{c}\text { QGAININT } \\
\text { KWh /Year] }\end{array}$ & 22902.78 & 22902.78 & 22902.78 & 22902.78 \\
\hline $\begin{array}{c}\text { QSOLGAIN } \\
{[\text { KWh /Year] }}\end{array}$ & 14769.44 & 14730.56 & 13055.56 & 14711.11 \\
\hline $\begin{array}{c}\text { QCOOL [KWh } \\
\text { /Year] }\end{array}$ & 309.89 & 310.65 & 302.88 & 316.16 \\
\hline
\end{tabular}

All these developed models allow not only an energy saving, but also provide a shade that is specific to the shape of the building, so this passive design strategy permits an economic saving on the overall cost of the ecocontainer building.

Configuration c shows an energy inertia that is explained by its compacity ratio (see Table 3) which is the lowest of all the designs, this ratio is defined, for the Poona climate.

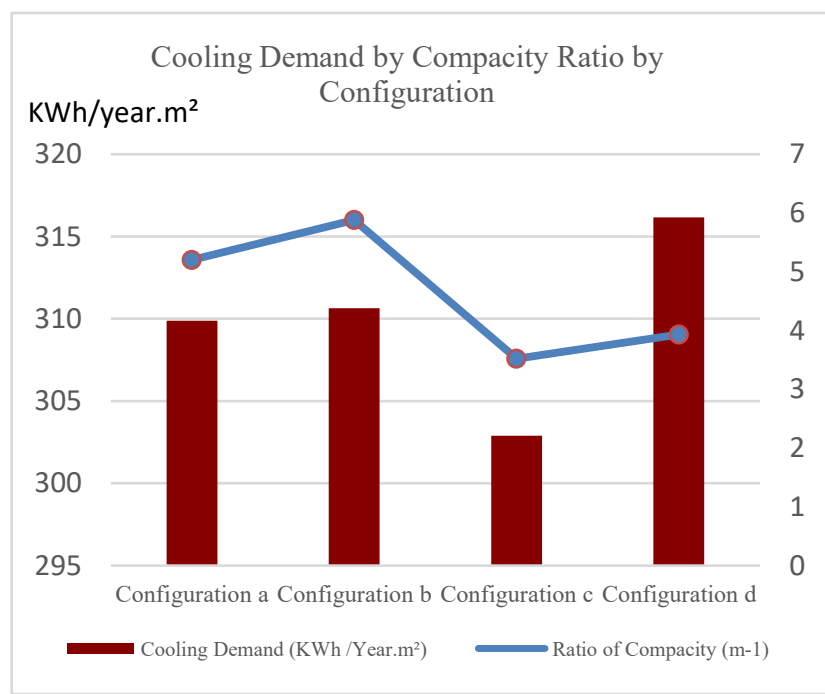

Fig. 7. Cooling Demand by Compacity Ratio and by Configuration. 
This type of architecture is recommended especially for its ecological approach; however, the energy approach must be done from the design phase and would be appropriate to India.

Figure 7 illustrates the correlation between the compacity ratio as defined by us and the air conditioning demand expressed by each of the configurations, and we can observe that the higher the compacity ratio, the greater the demand expressed.

Since configuration $\mathrm{c}$ is the one that has demonstrated the lowest demand in terms of air conditioning, and for this reason, the study is extended in more detail on this model, in order to better target the most critical period.

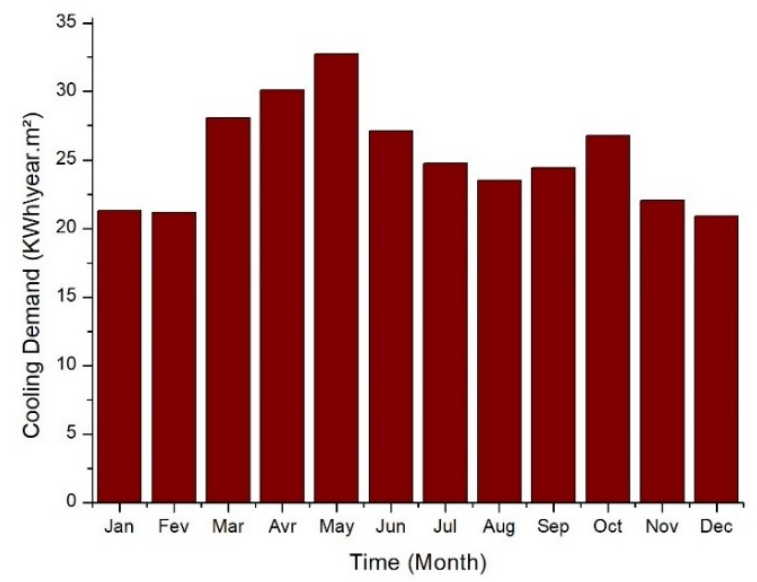

Fig. 8. Cooling demand per months of configuration c

The figure above (see Figure8) shows the cooling demand per month and over a whole year for configuration c. We observe that the most energyintensive period is from March to July. Nevertheless, for the rest of the year, consumption is more or less close.

\section{CONCLUSION}

Bioclimatic design is based on several parameters such as materials, orientation, wall composition, compacity, but also the climatic factor. The simulations carried out made it possible to evaluate the annual energy consumption of an eco-container used as elementary cells in our study, and shows the correlation between shape and energy in building sector.

With the resulting shape of the containers, the result is interesting not only from an architectural point of view but also in terms of energy. The dynamics of the stacked configurations has allowed the creation of new spaces that can take on another function, such as a terrace or even a garden, from a structural point of view the containers are designed to be stacked and juxtaposed.

This study represents the advantage of the construction of the container in semi-arid or even arid climates, the economic opportunity is such that today we can design, build and live in a container without fear of discomfort.
Given the results obtained, we will work on more complex shapes and thus enlarge the scale, move on to collective housing and the eco-neighbourhood, with taking into consideration the comfort of the user and compliance with the thermal regulations in force on the site concerned.

\section{References}

1. G. O. J. a. N. T. Roshan, Ene. Pol. 49. 731-739, (2012).

2. C.Hachem-Vermette, Sol Ene. 159. 710-721, (2018).

3. J. Vijayalaxmi, Loc Env. 15. 13. 245-259, (2010).

4. YASHADA, «Nati Symp on Nema Mana: Nematological Society of India and Indian Council of Agricultural Research (2015).

5. «International Organization for Standardization,» [En ligne]. Available: https://www.iso.org/aboutus.html. 